DR. WILLIAM D GAILLARD (Orcid ID : 0000-0001-5709-0033)

PROF. ALEXIS ARZIMANOGLOU (Orcid ID : 0000-0002-7233-2771)

DR. ARTHUR CUKIERT (Orcid ID : 0000-0002-6563-4149)

DR. JO M WILMSHURST (Orcid ID : 0000-0001-7328-1796)
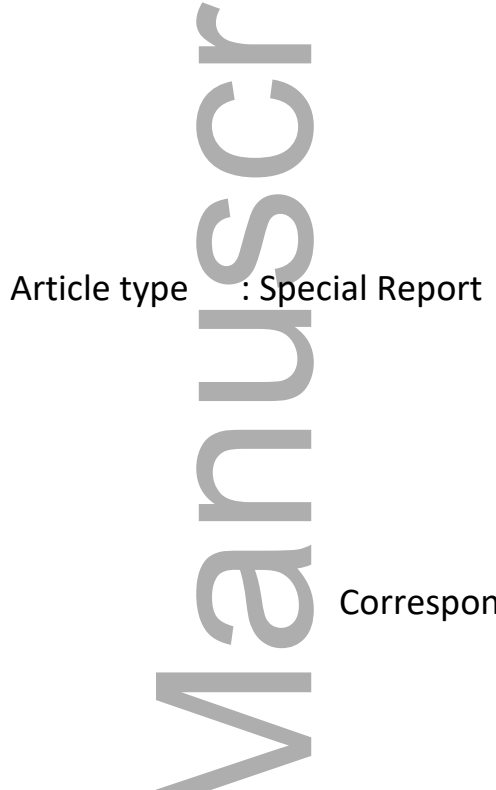

Corresponding author mail id: wgaillar@childrensnational.org

\title{
Establishing Criteria for Pediatric Epilepsy Surgery Centers Levels of Care: Report from the ILAE Pediatric Epilepsy Surgery Task Force
}

William D Gaillard ${ }^{1}$, Nathalie Jette ${ }^{2}$, Susan T Arnold ${ }^{3}$, Alexis Arzimanoglou ${ }^{4,5}$, Kees PJ Braun ${ }^{6}$, Arthur Cukiert ${ }^{7}$, Alexander Dick ${ }^{1}$, A Simon Harvey ${ }^{8}$, Julia Jacobs ${ }^{9}$, Bertil Rydenhag ${ }^{10}$, Vrajesh Udani ${ }^{11}$, Jo M Wilmshurst ${ }^{12}$, J Helen Cross ${ }^{13}$, Prasanna Jayakar ${ }^{14}$, and Task Force for Pediatric Epilepsy Surgery, Commission for Pediatrics, and the Surgical Commission of the International League Against Epilepsy*

*working group members listed below

This is the author manuscript accepted for publication and has undergone full peer review but has not been through the copyediting, typesetting, pagination and proofreading process, which may lead to differences between this version and the Version of Record. Please cite this article as doi: $\underline{10.1111 / \text { EPI.16698 }}$

This article is protected by copyright. All rights reserved 
${ }^{1}$ WD Gaillard, Center for Neuroscience, Children's National Medical Center, Washington DC USA

${ }^{2}$ Department of Neurology, Icahn School of Medicine at Mount Sinai, New York NY USA

${ }^{3}$ Division of Child Neurology, UT Southwestern Medical Center, Dallas TX USA

${ }^{4}$ Department of Pediatric Epileptology and Functional Neurology, University Hospitals of Lyon and Lyon Neuroscience Research Lyons France

${ }^{5}$ Epilepsy Unit, Child Neurology Dpt, Hospital San Juan de Dios, Barcelona, Spain

${ }^{6}$ Department of Child Neurology, University Medical Center Utrecht, Netherlands

${ }^{7}$ Department of Neurosurgery, San Paolo Epilepsy Clinic, San Paolo Brazil

${ }^{8}$ Department of Neurology, The Royal Children's Hospital, Melbourne Australia

${ }^{9}$ Department of Pediatrics and Clinical Neuroscience, Alberta Children's Hospital, University

of Calgary, Calgary Canada

${ }^{10}$ Division of Neurosurgery, University of Gothenburg, Institute of Neuroscience and

Physiology, Sahlgrenska Academy, Gothenburg Sweden

${ }^{11}$ Department of Neurology, P. D. Hinduja Hospital, Mumbai India

${ }^{12}$ Department of Paediatric Neurology, Red Cross War Memorial Children's Hospital,

Neuroscience Institute ,University of Cape Town, Cape Town, South Africa

${ }^{13}$ Neuroscienees Unit, , University College London, Great Ormond Street Institute of Child Health, London UK

${ }^{14}$ Department of Neurology, Nicklaus Children's Hospital, Miami FL USA

Member of the European Reference Network for Rare and Complex Epilepsies (ERN

EpiCARE):-Drs A Arzimanoglou, KP Braun, and JH Cross

Corresponding Author:

$\mathrm{W}^{\mathrm{m}}$ Davis Gaillard

Neurology

Children's National Medical Center

111 Michigan Ave NW

Washington DC 20010

This article is protected by copyright. All rights reserved 
USA

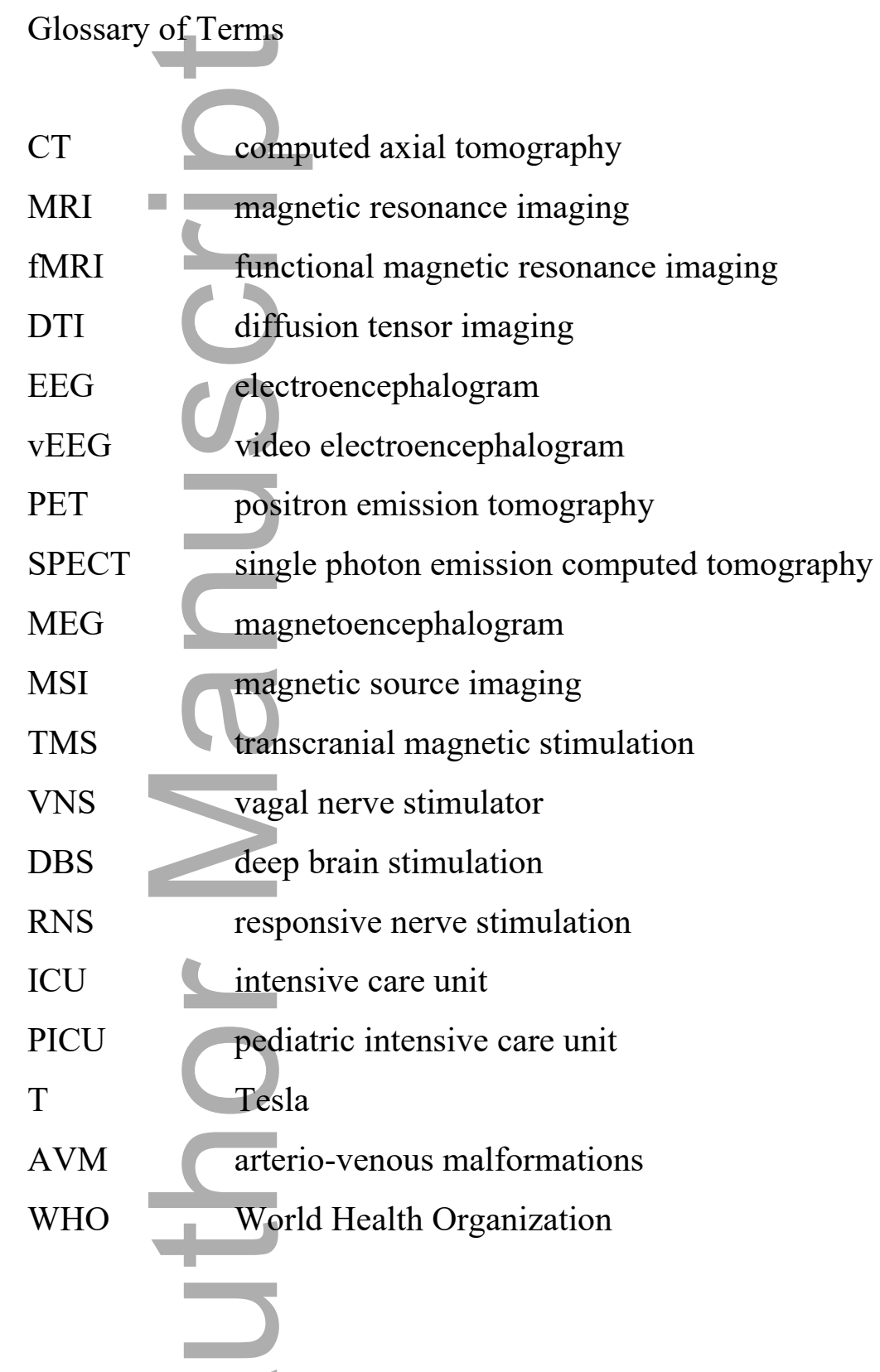

Number of text pages: 77 (23 not including cover page, abstract, figures, tables, references, or supplementary materials)

Number of words: $\mathbf{4 , 2 3 0}$ (not including cover page, abstract, figures, tables, references, or supplementary materials)

This article is protected by copyright. All rights reserved 
Number of figures: 3

Number of table: 3

ORCID number for William D. Gaillard, MD: 0000-0001-5709-0033

\begin{abstract}
Pre-surgical evaluation and surgery in the pediatric age group are unique in challenges related to caring for the very young, range of etiologies, choice of appropriate investigations, and surgical procedures. Accepted standards which define the criteria for levels of pre-surgical evaluation and epilepsy surgery care do not exist. Through a modified Delphi Process involving 61 centers with experience in pediatric epilepsy surgery across 20 countries, including low-middle to high income countries, we established consensus, for two levels of care. Levels were based on age, etiology, complexity of pre-surgical evaluation and surgical procedure. Competencies were assigned to the levels of care relating to personnel, technology, and facilities. Criteria were established when consensus was reached ( $\geq 75 \%$ agreement). Level 1 care consists of children age nine years and older, with discrete lesions including hippocampal sclerosis, undergoing lobectomy or lesionectomy, preferably on the cerebral convexity and not close to eloquent cortex, by a team including a pediatric epileptologist, pediatric neurosurgeon, and pediatric neuroradiologist with access to vEEG and 1.5T MRI. Level 2 care, also encompassing Level 1 care, occurs across the age span and range of etiologies (including tuberous sclerosis complex, Sturge-Weber syndrome, hypothalamic hamartoma) associated with MRI lesions that may be illdefined, multilobar, hemispheric or multifocal, and includes children with normal MRI or foci in/abutting eloquent cortex. Available Level 2 technologies includes 3T MRI, other advanced
\end{abstract}


MR technology including fMRI and DTI (tractography), PET and/or SPECT, source localization with EEG or MEG, and the ability to perform intra- or extra-operative invasive monitoring and functional mapping, by a large multi-disciplinary team, with pediatric expertise in epilepsy, neurophysiology, neuroradiology, epilepsy neurosurgery, neuropsychology, anesthesia, neurocritical care, psychiatry, and nursing. Levels of care will improve safety and outcomes for pediatric epilepsy surgery and provide standards for personnel and technology to achieve these levels.

\section{Key Points Box:}

1) Levels of pediatric epilepsy surgery care established by a modified Delphi method involving multidisciplinary epilepsy professionals from across the globe

2) Two levels of care established based on clinical complexities and institutional competencies

3) Standardized criteria designed to elevate care and improve safety of all infants and children with epilepsy undergoing epilepsy surgery

\section{Introduction}

The specific skills, procedures, and resources required for pre-surgical evaluation and epilepsy surgery in children have steadily gained acknowledgement over the past 30 years. Several efforts of the International League Against Epilepsy (ILAE) Pediatric Epilepsy Surgery Task Force have delineated the status of pediatric epilepsy surgery in an effort to gain visibility and standardize care. The number of pediatric epilepsy surgical procedures has increased over the last decade ${ }^{1,2}$, in contrast to adults. Nevertheless, there is an increasing recognition that epilepsy surgery in children is under-utilized ${ }^{3}$. Historically, epilepsy surgery was regarded as a treatment of last resort whereas more recently surgery is considered standard of care in appropriately selected patients, being superior to treatment with a third medication. ${ }^{4,5}$ There is also evidence that surgery may mitigate the detrimental effects of ongoing seizures and medications ${ }^{6}$, leading to improved cognition ${ }^{7,8}$ or prevention of further cognitive decline. ${ }^{9,10,11,12}$ 
as well as reduced morbidity and mortality. Furthermore, there is evidence that delays in epilepsy surgery increase the risks of not achieving seizure control, poor cognitive outcomes, and death. ${ }^{13,14,15}$

The first ILAE Epilepsy Surgery Task Force document ${ }^{16}$ acknowledged the unique characteristics of early age epilepsies and candidacy for surgery. Among these are the issue of brain development, the existence of age-specific epileptic syndromes, the prospect of plasticity with recovery of function, the pathological substrates and etiologies specific to the pediatric focal epilepsies, and the various surgical procedures performed. These features justify dedicated resources for specialty pediatric epilepsy surgery centers highlighting the importance of having pre-surgical evaluation and neurosurgery teams with specialized skills and settings - infants and children are not small adults. A set of standards were established for physicians detailing when to refer children with drug-resistant epilepsy to specialists. In the second document the range of the pathological substrates that occur in pediatric populations and types of surgical procedures was affirmed in a worldwide survey of 20 pediatric epilepsy surgery centers. ${ }^{17}$ A third document ${ }^{18}$ provided a range of views and consensus on the use of diagnostic testing for a range of pediatric entities determined by etiology/pathology. These recommendations were based on a literature review and consensus discussion, admittedly in the context of limited high-level evidence. Included was a recommendation for an epilepsy surgery evaluation pathway, priorities for diagnostic testing, and implementation of resection strategies including indications for invasive monitoring. A fourth document ${ }^{19}$ surveyed pediatric epilepsy neurosurgeons on current practice and surgical approaches, in the context of varying pathology and procedures, including technical aspects of operating room practice. This was followed by a survey of surgical practice patterns in children with epileptogenic foci near or in eloquent cortex along with recommendations for minimizing and reporting neurological deficits. ${ }^{20}$

These documents emphasize the special and particular needs of pediatric epilepsy surgical care. Epilepsy surgery is evolving in its standards for evaluation, consideration, and execution. The number of centers that perform epilepsy surgery in children has increased, yet the resources, expertise, candidacy, and practice patterns vary considerably; adult skills are not transferable to children. Many worldwide regions do not have designated epilepsy centers for 
surgical evaluation and may be unaware of the technology and skills required. The identification and consideration of a child as a surgical candidate ("presurgical care"), in addition to the selection of appropriate diagnostic tools and performance of surgery, includes knowledge of pediatric epilepsy, neuroanatomy, neurophysiology, and of the numerous technical approaches. For these reasons there remain gaps in the care of children with drug-resistant epilepsy who are potential candidates for epilepsy surgery. Here we seek to address these gaps by setting standards and resources necessary to achieve the aims delineated as levels of care. These efforts are not only necessary to set standards for basic and advanced epilepsy surgery care, but importantly serve as a resource for centers to achieve the technology, personnel, skills, and facilities to be a pediatric epilepsy and epilepsy surgery center. The manuscript also contributes to the Domain 4 (competencies 4.1 to 4.7 ) of the ILAE curriculum. ${ }^{21}$

Several countries have put forward varying forms of guidelines or standards for epilepsy surgery care (Chile, Brazil, Germany/Austria/Switzerland, England, China, United States; Table 1; See Supplementary Materials I for details). Some of these are legislated, some by selfauthorized oversight bodies, while others are consensus statements. They define single level or at most two levels of surgical care. When two levels are proposed the first level is more basic (lesionectomy, lobectomy) and the second level more complex care or procedures (e.g. hemispherectomy, eloquent cortex). The first level typically includes CT, MRI $(\leq 1.5 \mathrm{~T})$, and EEG; the second level typically includes higher field MRI (3T), DTI, PET, SPECT, and invasive monitoring of any kind. Few distinguish children as a separate entity. The English national Childhood Epilepsy Surgical Services (CESS) designate care of those younger than five years to certified pediatric centers only, and the Chileans place infants in Level Two centers but without other comment of pediatric expertise or designation. ${ }^{22}$ The American National Association of Epilepsy Centers (NAEC) offer a pediatric designation, but unlike the English, the American criteria do not address etiology, diagnostic complexity, or specify surgical procedures. ${ }^{23}$ Only the English and the American criteria include a system of auditing. The European Reference Network for Rare and Complex Epilepsies and the Chinese designate volume of evaluation and surgical procedures. ${ }^{24,25}$

Previous national efforts share some common elements, others hold unique elements, but all have limitations. They do, however, form the basis of ILAE efforts going forward to achieve 
worldwide consensus for these criteria, based on expert opinion and experience in a large group of professionals from different backgrounds. Here we delineate the elements of care and expertise necessary (e.g. personnel, technology, facilities) to perform pediatric epilepsy surgery according to different levels of care and to be considered a pediatric epilepsy surgery center. We also presume each center holds the commensurate skills and resources necessary to provide presurgical care for children with epilepsy.

\section{Methods}

A modified Delphi method was used ${ }^{26,27,28}$ (See Figure 1) to achieve consensus on aspects and elements of care. Items to be rated were generated, based on a literature review, by a core team (See Supplementary Materials II) according to complexity of care and competencies as elements for pediatric epilepsy surgery care (see below). Round I consisted of rating, on a seven-point scale, each item (134 Items, See Supplementary Materials III). The presumption was that two or three levels (basic, middle, advanced) of care would become evident from the responses from members of the ILAE pediatric surgery task force members (29 participants). However, the results demonstrated an absence of consensus on any items.

It was therefore decided at the Task Force meeting in Barcelona 2017, convened to review and discus survey results, to establish two levels of care and have up or down votes on elements of care required for each of these levels (Round II). Round II was further divided into two tiers of voting based on Complexities, Round IIA; and Competencies, Round IIB. Specifically, the two levels were established first by considering Complexities of care (age, etiology, complexity of pre-surgical evaluation, type of surgery) to decide what patients would be assigned to Level 1 (basic epilepsy surgery) or Level 2 (complex epilepsy surgery). Once levels were determined in the tier one survey (Round IIA), we then assigned Competencies to each of the two levels by vote in a second-tier vote (Round IIB) that included items related to the required technology (derived from commonly used and new technology advocated for epilepsy surgery evaluation and care), resources, personnel, and facilities for each level. For some items, access to resources not otherwise on site (i.e. rehabilitation, MEG, neuropathology) were deemed 
sufficient. Competencies were also considered for a series of particular clinical circumstances, such as infants, operating in or near eloquent cortex, and multifocal epilepsy.

The Round II questions were drafted, discussed, revised, and finalized by members of the core team. The methodological approach for Round IIA and then Round IIB were similar. The Round II questions were circulated to the wider participant group ( $\mathrm{n}=80$ members; Table 2 for participating members/sites). All voting was anonymous, was performed on an electronic platform entered directly into a RED Cap database, included feedback with questions, comments, and provided participants the opportunity to identify gaps in Round II items. Unclear items were clarified, and when necessary removed or substituted, and new items added. Consensus was defined as $75 \%$ agreement or more on a given item; items with $60-74 \%$ agreement were included in a subsequent round.

For round IIA, participants were asked, for each item, to select the type of center that was appropriate for each item (Level 1, level 2 or neither; See Supplementary Materials III). Initial voting, IIAi, involved 51 items. A second round of voting ( $\mathrm{n}=28$ items) ensued (IIAii) and included clarifying questions. In the second round (IIAii) results of the first round (IIAi) of voting were provided and members asked if they agreed with the majority, and if not to provide reasons for disagreement. A final, third round (IIAiii), occurred for a minority of items ( $\mathrm{n}=1$ item). Some items did not achieve consensus. After each round, results were tabulated and circulated to participants.

For round IIB, participants were asked, for each item, to select aspects of technology, personnel, resources/facilities, and experience that was appropriate (Level 1 or level 2 care, or neither; See Supplementary Materials III). Initial voting, IIBi, involved 159 items. A second round of voting ( $\mathrm{n}=53$ items) ensued (IIBii) and included clarifying questions. In the second round (IIBii) results of the first round (IIBi) of voting were provided and members asked if they agreed with the majority, and if not to provide reasons for disagreement. A final, third round (IIBiii), occurred for a minority of items ( $\mathrm{n}=5$ items). Some items did not achieve consensus. After each round, results were tabulated and circulated to participants. 
In the principal round of voting (Round II) we aimed to assure greater distribution across the globe as well as economic diversity. Eighty centers were invited from the following sources: participants in the pediatric neurosurgical survey ${ }^{19}$, sites identified as having epilepsy surgery centers for children from ILAE chapter lists, NAEC centers (for the USA), the European Reference Network for Rare and Complex Epilepsies, and ILAE pediatric epilepsy surgery task force members. Sixty-one centers participated in the principal (Round II) survey for Complexities and subsequently Competencies. Participating centers and collaborators are listed in Table 2 (See figure 2, Map). Results are descriptive based on 75\% agreement. It is presumed a case conference will occur with members of the specialty team to review history, clinical characteristics, results of diagnostic studies, and to agree on surgical options and approaches. ${ }^{18}$

\section{Results}

Participating Sites

Sixty-one centers out of 80 invited participated in the principal (Round II) survey. These centers represented 20 countries (Figure 2); 76\% came from WHO high income economies, 17\% upper middle income economies, and 7\% lower middle income economies. Of those answering surveys for their centers, $65 \%$ were neurologists, $27 \%$ neurosurgeons and $8 \%$ from other disciplines. Twenty-nine sites also conducted epilepsy surgery on adult patients. The number of first time epilepsy resections per year on patients 18 and younger (excludes VNS, or prior procedures for invasive monitoring) ranged from 2 to 165 , with a mean of 35, and a median of 28 (Figure 3).

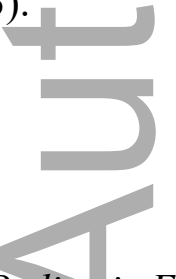

Level 1 Pediatric Epilepsy Surgery Center Criteria (see Table II)

$\underline{\text { Complexities }}$ 
Age: Children nine years and older, the same as the earlier neurosurgical consensus survey. ${ }^{19}$

Etiology: Children with single and discrete lesions on MRI, including tumors, well-defined focal cortical dysplasias, cavernomas, hippocampal sclerosis (single pathology), and cysticercosis.

Location/procedures: Lesionectomy, temporal lobectomy, amygdalo-hippocampectomy, resections on the cerebral convexity away from eloquent cortex, and placement of VNS.

\section{Competencies}

Personnel: Pediatric neurologist, at least one pediatric epileptologist (who is also a pediatric neurologist), a pediatric neurosurgeon, a pediatric neuroradiologist, an anesthesiologist skilled with children, and a social worker.

Technology: Should include the ability to perform routine EEG and prolonged video-EEG monitoring. Standard imaging includes CT and 1.5 T MRI using a dedicated epilepsy protocol. ${ }^{29}$, 30

Resources/Facilities: Include designated pediatric beds which may reside within an adult hospital but they must be clearly delineated as pediatric care, and a pediatric intensive care unit (PICU).

Experience: Evaluating and treating over 100 pediatric patients per year with epilepsy (median number subsequently accepted in second round vote). Minimum number of pediatric epilepsy surgeries, excluding VNS, is 15 per year.

\section{Level 2 Pediatric Epilepsy Surgery Center Criteria}

\section{$\underline{\text { Complexities }}$}


All Level 1 ages, etiologies, and surgical procedures are included in Level 2 care.

Age: children eight years and younger are restricted to level 2 centers.

Etiology/Lesion characteristics: Hippocampal sclerosis with dual pathology, arteriovenous malformations, encephalomalacia due to ischemic or other injury, hemispheric malformations of cortical development, post infectious/inflammatory conditions and Rasmussen's encephalitis, tuberous sclerosis complex, Sturge-Weber syndrome, and hypothalamic hamartoma are Level 2, as are MRI-negative patients and those with poorly demarcated or multiple lesions.

Location/procedures: In addition to temporal lobar and discrete convexity lesions, Level 2 locations include extra-temporal lobar, multilobar, hemispheric, multifocal, interhemispheric, and subcortical regions. Procedures may involve eloquent cortex, insula or basal regions. This indicates a range of procedures including corticectomy, lesionectomy, lobectomy, amygdalohippocampectomy, multi-lobar resection, hemispheric resections and disconnections, and resections in deep, interhemispheric and insular regions and eloquent cortex. Additional stimulation procedures include deep brain stimulation and responsive nerve stimulation, in addition to vagal nerve stimulation. Invasive intracranial monitoring including subdural and stereo EEG monitoring are Level 2 (see below).

Clinical characteristics of children undergoing epilepsy surgery only in level 2 centers include children with developmental regression/epileptic encephalopathy, specific developmental or medical syndromes, and genetic abnormalities. Comorbid, complicated medical problems (not further defined) and ongoing status epilepticus are also restricted to Level 2 centers.

\section{$\underline{\text { Competencies }}$}

Personnel: Includes a child neurologist, a minimum of two pediatric epileptologists, a pediatric neurophysiologist (who may also be a pediatric epileptologist), a pediatric epilepsy neurosurgeon preferably trained in functional/stereotactic epilepsy surgery, a pediatric neuro-radiologist, a 
pediatric neuropsychologist, a child psychiatrist, a pediatric anesthesiologist, a neuropathologist, a social worker, pediatric neurology nursing, a nutritionist/dietician, and a program coordinator.

Technology: Includes routine EEG, long-term video-EEG, CT, 3T MRI, functional MRI, DTI (white matter tractography), angiography, functional radio-ligand imaging (PET and/or SPECT), source localization capability (but not specified between high-density EEG or MEG, or fMRI/EEG). MRI follows a dedicated epilepsy protocol. ${ }^{29,30}$ Unique to Level 2 is the capacity for invasive EEG recording (intraoperative ECoG, subdural EEG, stereo EEG) and cortical stimulation mapping (intra- or extra-operative). Neuro-navigation, a widely available MRI based frameless system for intraoperative localization of brain structures and lesions before a resection is performed, is deemed standard of care.

Resources/Facilities: Dedicated pediatric services that may be linked to an adult facility or be free standing, a dedicated pediatric epilepsy monitoring unit (EMU) (NOT on adult floor/service), a dedicated PICU and access to rehabilitation facilities.

Experience: Evaluating and treating a minimum of 225 children with epilepsy a year in clinic (median number subsequently accepted in a second round vote) and conducting a minimum number of 20 epilepsy surgeries per year, excluding VNS. Twenty resections was the median number of epilepsy surgical procedures per year recommended from the initial vote. In a second vote the group then voted to accept 20 as the minimum number of definitive epilepsy surgical procedures per year.

\section{Other Level 2 Considerations.} -

While there was consensus not to split Level 2 further, there was near unanimous (95\%) or unanimous view that a subset of complexities were sufficiently unique to warrant specific competencies, thus perhaps suggesting a more specialized subset of level 2: There was a unanimous view that children younger than six months with multifocal epilepsy/lesions, a seizure focus in or near eloquent cortex, those with normal MRI or an indiscrete lesion were particular to specialized pediatric care. There was near unanimous ( $>95 \%)$ view for children less 
than 24 months; children with tuberous sclerosis complex, hypothalamic hamartoma, insula, multi-lobar (but not hemispheric) epilepsy/lesions belonged in a Level 2 setting.

A series of eight clinical circumstances that represent particular challenges were presented to ascertain consensus on additional competencies beyond those agreed upon for Level 2: 1) Epilepsy surgery in infants six months and younger, 2) children younger than 24 months, 3) operating near or in eloquent cortex, 4) operating on poorly demarcated lesions, 5) muti-lobar resection (without clear MRI abnormalities), 6) operating in insular cortex,7) children with tuberous sclerosis, and 8) hypothalamic hamartoma. Consensus was that a pediatric neuroanesthesiologist be available when operating on infants younger than 6 months of age. There are commonalities for those with normal MRI, ill-defined lesions, and multi-lobar abnormalities where two functional imaging modalities (PET, SPECT (as opposed to one or the other in Level 2). Insular surgery benefits from access to ictal/interictal SPECT. A minimally-invasive method of some form was deemed necessary for hypothalamic hamartoma surgery. fMRI is deemed standard for normal MRI and operating near or in eloquent cortex.

\section{No Consensus}

No agreement was achieved regarding corpus callosotomy being designated level 1 or 2 .

Similarly, level designation for the presence of psychiatric comorbidity or intellectual disability was not established.

Not Elements of Standard Care

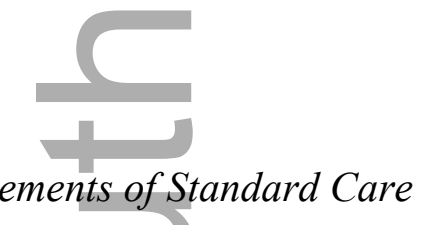

It is also notable that some technologies, especially newer technology, and facilities were not yet deemed essential or standard of care, including MEG, Transcranial Magnetic Stimulation (TMS), High Frequency Ultrasound (HiFUS), intraoperative MRI, minimally invasive surgery (of some form), and a dedicated Neuro PICU. 


\section{Discussion}

We present recommendations for two levels of pediatric epilepsy surgery care, Level 1 basic care and Level 2 advanced care, founded on the unique features of patient complexity including age, etiology, and location/procedure and center competencies including personnel, technology, facilities, and case volume. Children age 8 years and below should receive care at Level 2 Centers. The goal of establishing criteria is to elevate care, and improve safety of all infants and children with epilepsy undergoing epilepsy surgery, and allows centers to petition for resources, technology, and personnel.

Our levels of care and delineation of technology and personnel match previous guidelines and standards. Ours differ by bringing several elements together, determined by consensus through a Delphi process of successive and tiered votes, among more than 60 international pediatric epilepsy centers, and incorporate pediatric specific skills. The choice of age eight years as a major threshold of complexity (Level 2) matches the views from the prior neurosurgical survey. ${ }^{19}$ There is strong agreement that the younger the patient, the more essential it is that the child be cared for by a pediatric epilepsy specialty unit. This proposed view is concordant, with some modification, to the Chilean and English regulations. There was (near) unanimous view that the youngest ( $<24$ months of age, especially $<6$ months) require advanced and skilled teams for pre-surgical and surgical care. Beyond age, commonalities for Level 2 include an array of advanced structural and functional imaging technologies, the capacity for intracranial EEG monitoring and cortical stimulation, and pediatric specialty personnel.

Other guidelines generally do not comment on experience, either in patients seen or in children operated upon. There are some data to suggest that one needs to operate (resections/disconnections) on 15 patients with epilepsy per year to maintain skills as outcomes; adverse perioperative events are greater when volume falls below $15 .{ }^{31}$ For these reasons 15 is considered the minimum number of resections for a Level 1 center. For Level 2 centers, 20 is deemed the minimum but further study may be needed to ascertain numbers needed to establish and maintain advanced operative skills. We chose as another minimum the number of children 
with epilepsy evaluated each year, viewing the number of children evaluated for epilepsy surgery to be more open to variable interpretation. Previous work stressed the importance of case conferences for any level of care. ${ }^{18}$

There were some areas where consensus was not reached; by default they are assumed to fall within Level 2 but not excluded from level 1. The introduction of technology is a major part of epilepsy surgery evaluation. A challenge with diagnostic and therapeutic technology is that high-quality studies to evaluate their utility are often lacking to achieve class 1 or class 2 evidence status, especially in children. ${ }^{32} \mathrm{New}$ technology is often expensive with a poorly defined utility, but often assumed added diagnostic value. Thus, MEG is often valued but not deemed standard, similarly intra-operative MRI, and TMS are relatively new technologies that are used by some centers but not commonly accepted in practice. 3T MRI appears to have been accepted as standard practice, and may have helped change practice. It is unclear what the role $7 \mathrm{~T}$ MRI or post processing image algorithms will assume in the future, as well as technology yet to be developed. $33,34,35$

There will be exceptions and differences of view with implementing these standards. For example, cavernomas may be multifocal whereas a younger child may have a clearly distinct lesion outside of eloquent cortex. Cysticercosis is viewed as a distinct lesion but those hailing from areas where cysticercosis is endemic thought it a Level 2 and not a Level 1 entity, based on complex subtleties of the entity and decision making as to whether surgery is required. Several participants commented that additional skills may be required to ascertain whether hippocampal sclerosis is isolated or accompanied by dual pathology. While the treatment of AVMs was considered by many as standard neurosurgical care, when accompanied by epilepsy it was deemed specialty care for level 2 centers. Similarly, although VNS placement can be performed at Level 1 centers, excluding candidacy for resective surgery is important and may require diagnostic competencies available at level 2 centers.

There are limitations to this effort. The survey was conducted mainly by experienced epilepsy center directors, or senior members of established epilepsy programs, who may carry a bias for particular technologies, etiologies, or procedures. While we have identified the needs for 
pediatric epilepsy surgery, the evaluation cannot take place without a setting for pediatric epilepsy care. This is implied in the personnel, technology, and patient volumes presented but not a primary purpose of this endeavor. Comment was not made on epilepsy genetics, increasingly central to pediatric neurology, let alone epilepsy care, including the consideration of surgical candidacy. ${ }^{36}$ The ability to care for children with genetic epilepsies is noted in complexities for Level 2 but specific expertise in epilepsy genetics was not considered. We did not address range of medical complexities that may be present. We have also not surveyed the specifics of what technology is needed in the operating room other than neuro-navigation systems; many of these needs, however, are covered in the previous neurosurgical survey. ${ }^{19}$

Nor have we defined what is considered an expert and the pathway of training to achieve expertise. A previous ILAE Pediatric Epilepsy Surgery Task Force survey (unpublished observations) noted wide ranging experience in training of pediatric neurologists, epileptologists, and neurophysiologists, and more variability in the training of pediatric epilepsy neurosurgeons. In some countries, epileptologists are also trained as electrophysiologists, in others the two are distinct disciplines. A future task will be to define the training and experience necessary to be an expert.

Finally, resource limited economies are less well represented in this survey. Yet, expertise and technology are critical for specialty care and it is hoped that by delineating these features it will be easier to petition for the requisite training and technology necessary to improve and standardize care in these settings.

We proposed criteria for epilepsy centers so that programs will have the equipment, personnel, skills, and volume to optimize outcomes and elevate quality of care. We do not aim to deny care to children in resource-limited regions of the world where Level 1 centers do not exist. Such children may be offered epilepsy surgery at facilities without all the corresponding competencies, resources, and experience outlined above, but they would not be deemed to be epilepsy centers. Rather the long-term aim is to build the necessary resources and experience outlined here, step by step. While we have stated the requirements for Level 2 care, that does not preclude Level 1 centers from incorporating Level 2 technology and personnel. For example, 3T 
MRI, or some form of functional imaging, strengthens the armamentarium at that institution and may help identify children with a previously unrecognized focal and operable abnormalities.

\section{Conclusion}

We identified two levels of care based on complexities and competencies, with volume of patient care/experience, and minimum number of annual and epilepsy surgery resections. The basic Level 1 center cares for children 9 years and older, with a single defined lesion, employing a pediatric epileptologist and a general pediatric neurosurgeon, utilizing video-EEG, and $1.5 \mathrm{~T}$ MRI. The advanced Level 2 center cares for children of all ages, in a pediatric setting, with a team of skilled pediatric clinicians trained in neurology, epilepsy, neurophysiology, neuroimaging, and pediatric epilepsy surgery. Level 2 centers utilize an array of advanced diagnostic technology including 3T MRI, fMRI, PET or SPECT; have invasive EEG monitoring capacity; conduct surgery in those with normal MRI, involvement near and in eloquent cortex, and deep lesions; and, provide specialty service on the in-patient floor, PICU, and rehabilitation services. An argument can be made for additional skills and technology in those younger than 24 months, and those with multi-lobar or deep lesions. Future efforts should include defining criteria for specialty training. The goal of establishing criteria is to elevate care, and improve safety of all infants and children with epilepsy undergoing epilepsy surgery and allows centers to petition for resources, technology, and personnel.

\section{Acknowledgements and Disclosures.}

ILAE statement: This report was written by a team selected by the International League Against Epilepsy (ILAE) and was approved for publication by the ILAE. Opinions expressed by the authors, however, do not necessarily represent official policy or the position of the ILAE. The authors had no relevant conflicts of interest to declare.

We thank Rachel Reed for assistance in preparing the manuscript. 


\section{Ethical Publication Statement.}

We confirm that we have read the Journal's position on issues involved in ethical publication and affirm that this report is consistent with those guidelines.
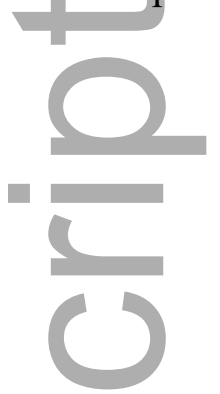

\section{References}

1. Lamberink HJ, Boshuisen K, van Rijen PC, Gosselaar PH, Braun KP; Dutch Collaborative Epilepsy Surgery Program. Changing profiles of pediatric epilepsy surgery candidates over time: a nationwide single-center experience from 1990 to 2011. Epilepsia. 2015; 56: 717- 25.

2. Baud MO, Rao VR. Gauging Seizure Risk. Neurology.2018;91: 967-973

3. Pestana-Knight EM, Schiltz NK, Bakaki PM, Koroukian SM, Lhatoo SD, Kaiboriboon K. Increasing utilization of pediatric epilepsy surgery in the United States between 1997 and 2009. Epilepsia. 2015;56:375-81.

4. Dwivedi R, Ramanujam B, Chandra PS, Sapra S, Gulati S, Kalaivani M, et al. Surgery for Drug-Resistant Epilepsy in Children. N Engl J Med. 2017;377:1639-1647.

5. Wiebe S, Blume WT, Girvin JP, Eliasziw M; Effectiveness and Efficiency of Surgery for Temporal Lobe Epilepsy Study Group. A randomized, controlled trial of surgery for temporal-lobe epilepsy. N Engl J Med. 2001;345:311-8.

6. Honda R, Kaido T, Sugai K, Takahashi A, Kaneko Y, Nakagwa E, et al.

Long-term developmental outcome after early hemispherotomy for hemimegalencephaly in infants with epileptic encephalopathy. Epilepsy Behav. 2013;29:30-5.

7. Skirrow C, Cross JH, Cormack F, Harkness W, Vargha-Khadem F, Baldeweg T. Longterm intellectual outcome after temporal lobe surgery in childhood. Neurology. 2011;76:1330-7. 
8. Skirrow C, Cross JH, Harrison S, Cormack F, Harkness W, Coleman R, et al. Temporal lobe surgery in childhood and neuroanatomical predictors of long-term declarative memory outcome. Brain. 2015;138(Pt 1):80-93.

9. Smith ML, Elliott IM, Lach L. Cognitive, psychosocial, and family function one year after pediatric epilepsy surgery. Epilepsia. 2004;45:650-60.

10. Elliott IM, Lach L, Kadis DS, Smith ML. Psychosocial outcomes in children two years after epilepsy surgery: has anything changed? Epilepsia. 2008;49:634-41.

11. Jonas R, Asarnow RF, LoPresti C, Yudovin S, Koh S, Wu JY, et al. Surgery for symptomatic infant-onset epileptic encephalopathy with and without infantile spasms. Neurology. 2005;64:746-50.

12. Pulsifer MB, Brandt J, Salorio CF, Vining EP, Carson BS, Freeman JM. The cognitive outcome of hemispherectomy in 71 children. Epilepsia. 2004;45:243-54.

13. Simasathien T, Vadera S, Najm I, Gupta A, Bingaman W, Jehi L. Improved outcomes with earlier surgery for intractable frontal lobe epilepsy. Ann Neurol. 2013;73:646-54.

14. Blumcke I, Spreafico R, Haaker G, Coras R, Kobow K, Bien CG, et al. Histopathological Findings in Brain Tissue Obtained during Epilepsy Surgery. N Engl J Med 2017;377:1648-1656.

15. Braun KPJ, Cross JH. Pediatric epilepsy surgery: the earlier the better. Expert Rev Neurother. 2018;18:261-263.

16. Cross JH, Jayakar P, Nordli D, Delalande O, Duchowny M, Wieser HG, et al. Proposed criteria for referral and evaluation of children for epilepsy surgery: recommendations of the Subcommission for Pediatric Epilepsy Surgery. Epilepsia. 2006; 47:952-9.

17. Harvey AS, Cross JH, Shinnar S, Mathern GW; ILAE Pediatric Epilepsy Surgery Survey Taskforce.Defining the spectrum of international practice in pediatric epilepsy surgery patients. Epilepsia. 2008;49:146-55.

18. Jayakar P, Gaillard WD, Tripathi M, Libenson MH, Mathern GW, Cross JH; Task Force for Paediatric Epilepsy Surgery, Commission for Paediatrics, and the Diagnostic Commission of the International League Against Epilepsy. Diagnostic test utilization in evaluation for resective epilepsy surgery in children. Epilepsia. 2014;55:507-18. 
19. Cukiert A, Rydenhag B, Harkness W, Cross JH, Gaillard WD; Task Force for Pediatric Epilepsy Surgery for the ILAE Commissions of Pediatrics and Surgical Therapies. Technical aspects of pediatric epilepsy surgery: Report of a multicenter, multinational web-based survey by the ILAE Task Force on Pediatric Epilepsy Surgery. Epilepsia. $2016 ; 57: 194-200$.

20. Jayakar P, Jayakar A, Libenson M, Arzimanoglou A, Rydenhag B, Cross JH, et al. Epilepsy surgery near or in eloquent cortex in children-Practice patterns and recommendations for minimizing and reporting deficits. Epilepsia.2018;59:1484-1491.

21. Blümcke I, Arzimanoglou A, Beniczky S, Wiebe S, The EpiEd Task Force. Roadmap for a competency-based educational curriculum in epileptology: report of the Epilepsy Education Task Force of the International League Against Epilepsy. Epileptic Disorders. 2019;21:129-140.

22. Epilepsy Action. (n.d.). Children's Epilepsy Surgery Service (CESS) in England. Retrieved from https://www.epilepsy.org.uk/info/treatment/surgery/children 23. National Association of Epilepsy Center. (n.d.). Guidelines for Centers. Retrieved from https://www.naec-epilepsy.org/about-epilepsy-centers/guidlines-for-centers/

24. Epicare. (n.d.).European Reference Network. Retrieved from https://epi-care.eu/epicareerns-position-regarding-the-new-ern-application-call/

25. Wang YP and China Association Against Epilepsy. The China epilepsy center classification standard (trial) revised in 2016, J Epilepsy 2017;3:243-247[Chinese]

26. Jones J, Hunter D. Consensus methods for medical and health services research. BMJ. 1995;311:376-80.

27. Fitch K, Bernstein SJ, Aguilar MD, Burnand B, LaCalle JR, Lazaro P, et al. The RAND/UCLA Appropriateness Method User's Manual. RAND 2001.

28. Nair R, Aggarwal R, Khanna D. Methods of formal consensus in classification/diagnostic criteria and guideline development. Semin Arthritis Rheum. 2011;41:95-105.

29. Gaillard WD, Chiron C, Cross JH, Harvey AS, Kuzniecky R, Hertz-Pannier L, et al. Guidelines for Imaging Infants and Children with Recent-Onset Epilepsy. Epilepsia 2009;50:2147-53.

30. Bernasconi A, Cendes F, Theodore WH, Gill RS, Koepp MJ, Hogan RE, et al. Recommendations for the use of structural magnetic resonance imaging in the care of 
patients with epilepsy: A consensus report from the International League Against Epilepsy Neuroimaging Task Force. Epilepsia. 2019;60:1054-1068.

31. Englot DJ, Ouyang D, Wang DD, Rolston JD, Garcia PA, Chang EF. Relationship between hospital surgical volume, lobectomy rates, and adverse perioperative events at US epilepsy centers. J Neurosurg. 2013 ;118:169-74.

32. Gaillard WD, Cross JH, Duncan JS, Stefan H, Theodore WH; Task Force on Practice Parameter Imaging Guidelines for International League Against Epilepsy, Commission for Diagnostics. Epilepsy imaging study guideline criteria: commentary on diagnostic testing study guidelines and practice parameters. Epilepsia. 2011;52:1750-6.

33. Veersema TJ, Ferrier CH, van Eijsden P, Gosselaar PH, Aronica E, Visser F, et al. Seven tesla MRI improves detection of focal cortical dysplasia in patients with refractory focal epilepsy. Epilepsia Open. 2017;2:162-171.

34. Colon AJ, Osch MJPV, Buijs M, Grond JVD, Hillebrand A, Schijns O, et al. MEGguided analysis of 7T-MRI in patients with epilepsy. Seizure. 2018 ;60:29-38

35. Feldman RE, Delman BN, Pawha PS, Dyvorne H, Rutland JW, Yoo J, et al. 7T MRI in epilepsy patients with previously normal clinical MRI exams compared against healthy controls. PLoS One. 2019;14:e213642

36. Stevelink R, Sanders MW, Tuinman MP, Brilstra EH, Koeleman BP, Jansen FE, et al. Epilepsy surgery for patients with genetic refractory epilepsy: a systematic review. Epileptic Disord. 2018;20:99-115.

37. Surges R, et al. Tasks and Structure of Modern Epilepsy Centers in Germany. Akt Neurol. 2018; 45: 513-533

38. Bösebeck F, Beckenfeld R, Kurlemann G et al., Mitteillungen der AG Ambulante Epileptologie der DGfE: Revision der Kriterien Für die Anerkennug als EpilepsieAmbulanz oder Epilepsie-Schwerpunktpraxis. Z Epileptol 2016;29:35-39.

39. Rosenow F, Bast T, Czech T, Feucht M, Hans VH, Helmstaedter C, et al. Revised version of quality guidelines for presurgical epilepsy evaluation and surgical epilepsy therapy issued by the Austrian, German, and Swiss working group on presurgical epilepsy diagnosis and operative epilepsy treatment. Epilepsia. 2016;57:1215-20. 


\section{* Other Members Who Participated in the Study}

Mario A. Alonso-Vanegas, National Institute of Neurology and Neurosurgery

Carmen Barba, University of Florence

Lixin Cai, Pediatric Epilepsy Center, Peking University First Hospital

Sarat Chandra, All India Institute of Medical Sciences

Hsin-Hung Chen, Taipei Veteran's General Hospital

Mathilde Chipaux, Rothschild Foundation Hospital

Chun Kee Chung R, Seoul National University

Mary Connolly, University of British Columbia

Luca Del Palma, Sapienza University

Petia Dimova, St. Ivan Rilski University Hospital, Sofia, Bulgaria

Jason Doescher, Minnesota Epilepsy Group

Elizabeth Donner, Hospital for Sick Children, University of Toronto

Deepak Gill, The Children's Hospital at Westmead

Ajay Gupta, Cleveland Clinic

Michael Handler, Colorado Children's Hospital

Adam Hartman, Johns Hopkins Hospital

J (Hans) Holthausen, Schon Kliniken

Sergiusz Józwiak, Medical University of Warsaw

Philippe Kahane, Grenoble-Alpes University and Hospital

Lakshminarayanan Kannan, Gleneagles Global Hospitals

Kensuke Kawai, Jichi Medical University

Jack Kerrigan, Phoenix Children's Hospital

Sudha Kessler, Children's Hospital of Philadelphia

Pavel Krsek, Motol University Hospital, Prague

Jianxiang Liao, Shenzhen Children's Hospital

Mark Libenson, Boston Children's Hospital

Xian Lun Zhu, Prince of Wales Hospital, University of Hong Kong

Helio Machado, University of Ribeirao Preto

Wirginia Maixner, The Royal Children's Hospital

Stephen Malone, The University of Queensland 
Timothy Martland, Central Manchester University Hospitals

Gary Mathern, University of California Los Angeles

Ailsa McLellan, the Royal Hospital for Sick Children

Liisa Metsahonkala, Helsinki University Hospital

Doug Nordli, University of Chicago

Jeff Ojeman, Seattle Children's Hospital, University of Washington

Chima Oluigbo, Children's National Medical Center

Ashok Pillai, Amrita Institute of Medical Sciences

Tilman Polster, Mara Hospital, Bethel Epilepsy Centre

Hugo Pomata, Comprehensive Epilepsy Centre, Institute for Neurological Research

Vinayan K Puthenveettil, Amrita Institute of Medical Sciences

Victoria San Antonio, Barcelona Children's Hospital

Didier Scavarda, Aix-Marseille University / La Timone Hospital in Marseille

Benedict MSelladurai, Hospital Universiti Kebangsaan Malaysia

Shlomo Shinnar, Montifiore Hospital, Einstein University

Piradee Suwanpakdee, Phramongkutklao hospital

Laura Tassi, Claudio Munari Epilepsy Surgery Center, Ospedale Niguada

Agnes Trebuchon, Aix-Marseille University / La Timone Hospital in Marseille

Yi Wang, Children's Hospital of Fudan University

Howard Weiner, Texas Children's Hospital, Baylor University

Jim Whelass, Memphis Children's Hospital

Elaine Wirrell, Mayo Clinic

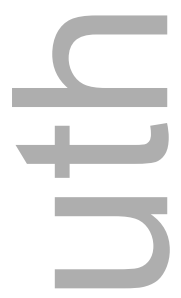

Figure 1. Delphi Process Flow Chart: Through a modified Delphi Process we established consensus, for two levels of care. Round I consisted of rating, on a seven-point scale, each item. Round II was further divided into two tiers of voting based on Complexities, Round IIA; and Competencies, Round IIB. A second round of voting ensued (IIAii) and included clarifying questions. A final, third round (IIAiii), occurred for a minority of items. Initial voting, IIBi 
occurred and then a second round of voting ensued (IIBii) and included clarifying questions. A final, third round (IIBiii), occurred for a minority of items.

Figure 2. Map of Survey Participants: Participation involved 61 centers with experience in pediatric epilepsy surgery across 20 countries, including low-middle through to high income countries.

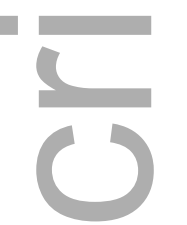

Figure 3. Surgical Resections Per Year by Sites: The mean number of surgical resections per year was 35 and the median was 28 .

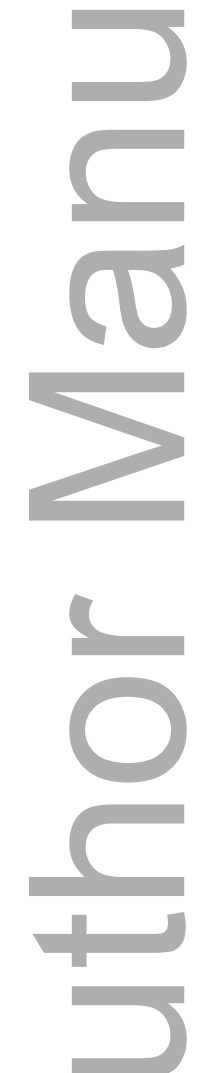

Table 1: Worldwide Epilepsy Surgery Criteria

\begin{tabular}{|c|c|c|c|c|c|c|c|}
\hline Feature & $\begin{array}{l}\text { USA } \\
\text { NAEC }\end{array}$ & Brazil & $\begin{array}{l}\text { Chil } \\
\text { e }\end{array}$ & $\begin{array}{l}\text { Europe } \\
\text { ERN }\end{array}$ & $\begin{array}{l}\text { England } \\
\text { CESS }\end{array}$ & $\begin{array}{l}\text { German } \\
\text { Speakin } \\
\text { g }\end{array}$ & China \\
\hline
\end{tabular}




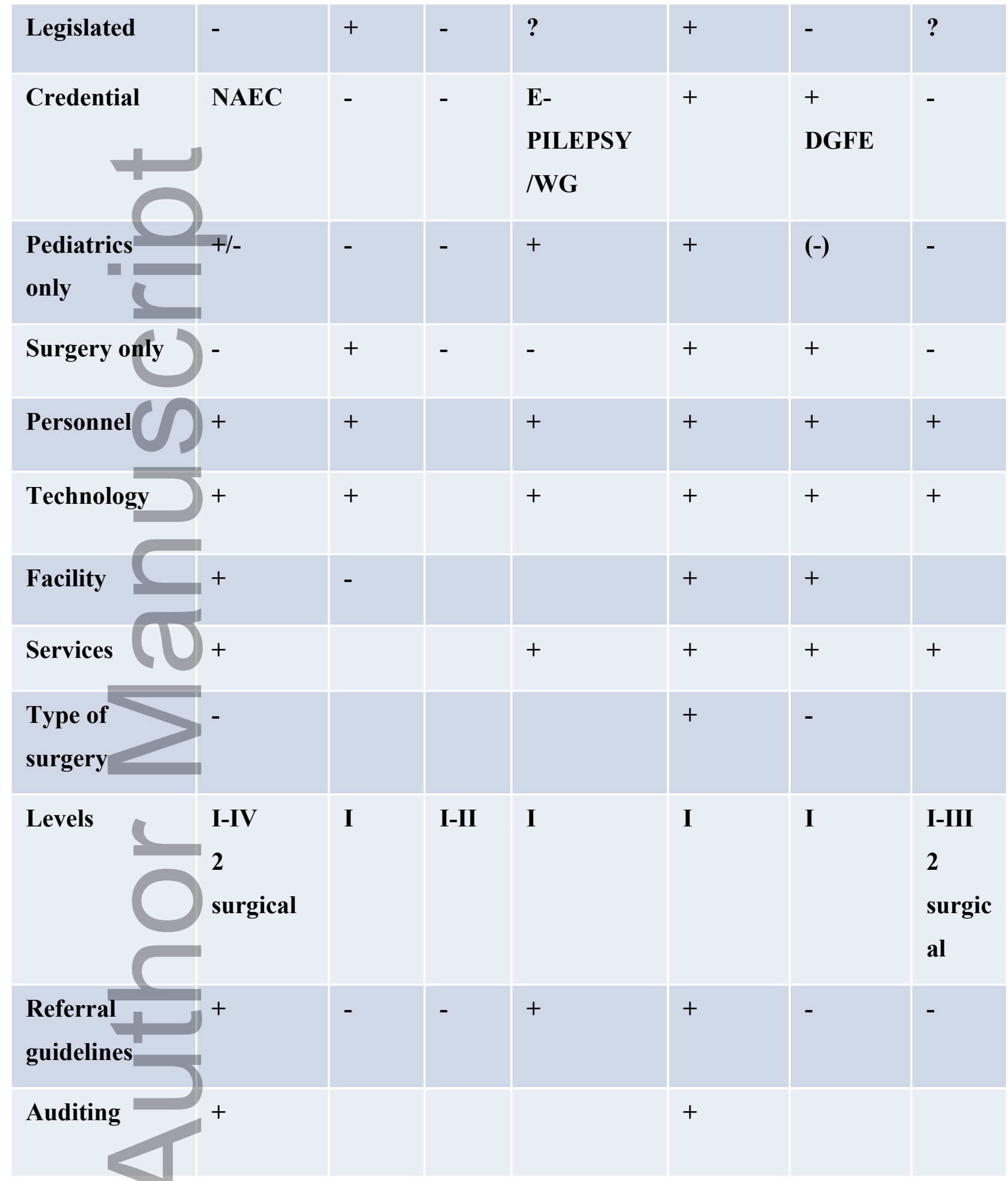

*NAEC: National Association of Epilepsy Centers

ERN: European Reference Network

CESS: Children's Epilepsy Surgery Service

DGFE: Deutsche Gesellschaft für Erziehungswissenschaft (German Society for Epileptology) 
Table 2: Survey Participants and Sites

\section{USA (18)}

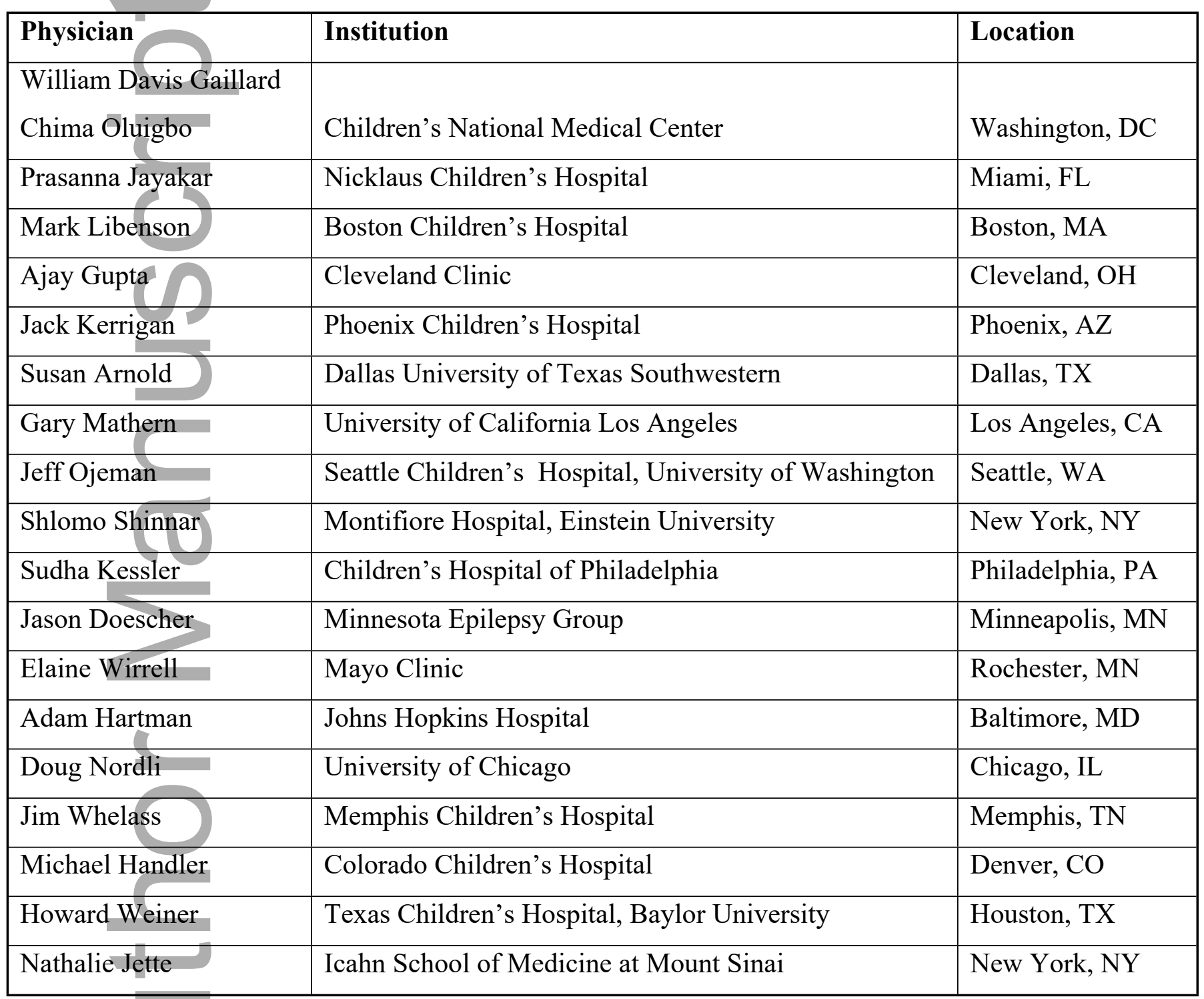

\section{Canada (2)}

\begin{tabular}{|l|l|l|}
\hline Physician & Institution & Location \\
\hline Elizabeth Donner & Hospital for Sick Children, University of Toronto & Toronto, ON \\
\hline Mary Connolly & University of British Columbia & Vancouver, BC \\
\hline
\end{tabular}




\section{Europe (20)}

\begin{tabular}{|c|c|c|}
\hline Physician & Institution & Location \\
\hline $\begin{array}{l}\text { J Helen Cross, Martin } \\
\text { Tisdall }\end{array}$ & $\begin{array}{l}\text { Great Ormond Street Hospital for Sick Children, } \\
\text { University College London }\end{array}$ & $\begin{array}{l}\text { London, United } \\
\text { Kingdom }\end{array}$ \\
\hline Timothy Martland & Central Manchester University Hospitals & $\begin{array}{l}\text { Manchester, } \\
\text { United Kingdom }\end{array}$ \\
\hline Ailsa McLe & The Royal Hospital for Sick Children & $\begin{array}{l}\text { Edinburgh, United } \\
\text { Kingdom }\end{array}$ \\
\hline Tilman Polste & Mara Hospital, Bethel Epilepsy Centre & $\begin{array}{l}\text { Bielelfeld, } \\
\text { Germany }\end{array}$ \\
\hline J (Hans) Holthausen & Schon Kliniken & $\begin{array}{l}\text { Vogtareuth, } \\
\text { Germany }\end{array}$ \\
\hline Julia Jacobs & University Medical Center Freiburg & Freiburg, Germany \\
\hline Kees P Braun & University Medical Center Utrecht & $\begin{array}{l}\text { Utrecht, } \\
\text { Netherlands }\end{array}$ \\
\hline Bertil Rydenhag & University of Gothenburg & $\begin{array}{l}\text { Gothenburg, } \\
\text { Sweden }\end{array}$ \\
\hline Liisa Metsahonkala & Helsinki University Hospital & Helsinki, Finland \\
\hline Laura Tassi & $\begin{array}{l}\text { Claudio Munari Epilepsy Surgery Center, Ospedale } \\
\text { Niguada }\end{array}$ & Milan, Italy \\
\hline Luca Del Palma & Sapienza University & Rome, Italy \\
\hline Carmen Barba & University of Florence & Florence, Italy \\
\hline Alexis Arzimanoglou & $\begin{array}{l}\text { University Hospitals of Lyon and Lyon Neuroscience } \\
\text { Research Centre }\end{array}$ & Lyon, France \\
\hline Mathilde Chipaux & Rothschild Foundation Hospital & Paris France \\
\hline $\begin{array}{l}\text { Didier Scavarda and } \\
\text { Agnes Trebuchon }\end{array}$ & $\begin{array}{l}\text { Aix-Marseille University / La Timone Hospital in } \\
\text { Marseille }\end{array}$ & Marseille, France \\
\hline $\begin{array}{l}\text { Victoria San Antonio, } \\
\text { Alexis Arzimanoglou }\end{array}$ & Barcelona Children's Hospital & Barcelona, Spain \\
\hline Pavel Krsek & Motol University Hospital, Prague & Prague, Czeck \\
\hline
\end{tabular}




\begin{tabular}{|l|l|l|} 
& & Republic \\
\hline Petia Dimova & St. Ivan Rilski University Hospital, Sofia, Bulgaria & Sofia, Bulgaria \\
\hline Sergiusz Józwiak & Medical University of Warsaw & Warsaw, Poland \\
\hline Philippe Kahane & Grenoble-Alpes University and Hospital & Grenoble, France \\
\hline
\end{tabular}

\section{South/Central America (4)}

\begin{tabular}{|l|l|l|}
\hline Physician & Institution & Location \\
\hline Arthur Cukiert & San Paolo Epilepsy Clinic & San Paolo, Brazil \\
\hline & $\begin{array}{l}\text { Comprehensive Epilepsy Centre, Institute for } \\
\text { Hugo Pomata }\end{array}$ & $\begin{array}{l}\text { Neurological Research, Buenos Aries } \\
\text { Argentina }\end{array}$ \\
\hline $\begin{array}{l}\text { Mario A. Alonso- } \\
\text { Vanegas }\end{array}$ & National Institute of Neurology and Neurosurgery & $\begin{array}{l}\text { Mexico City, } \\
\text { Hexico }\end{array}$ \\
\hline Helio Machado & University of Ribeirao Preto & San Paolo, Brazil \\
\hline
\end{tabular}

Africa (1)

\begin{tabular}{|l|l|l|}
\hline Physician & Institution & Location \\
\hline Jo Wilmshurst & University of Cape Town & $\begin{array}{l}\text { Cape Town, } \\
\text { South Africa }\end{array}$ \\
\hline
\end{tabular}

\section{Australia (3)}

\begin{tabular}{|l|l|l|}
\hline Physician & Institution & Location \\
\hline Deepak Gill & The Children's Hospital at Westmead & Sydney, Australia \\
\hline $\begin{array}{l}\text { Simon Harvey/Wirginia } \\
\text { Maixner }\end{array}$ & The Royal Children's Hospital & $\begin{array}{l}\text { Melbourne, } \\
\text { Australia }\end{array}$ \\
\hline Stephen Malone & The University of Queensland & $\begin{array}{l}\text { Brisbane, } \\
\text { Australia }\end{array}$ \\
\hline
\end{tabular}

\section{Asia (13)}


WD Gaillard 30

\begin{tabular}{|c|c|c|}
\hline Physician & Institution & Location \\
\hline Sarat Chandra & All India Institute of Medical Sciences & New Dehli, India \\
\hline Lakshminarayanan & & \\
\hline Kannan & Gleneagles Global Hospitals & Chennai, India \\
\hline $\begin{array}{l}\text { Ashok Pillai, Vinayan } \\
\text { K Puthenveettil }\end{array}$ & Amrita Institute of Medical Sciences & Kerala, India \\
\hline Vrajesh Udani & P. D. Hinduja Hospital & Mumbai, India \\
\hline Xian Lun Zhu & Prince of Wales Hospital Univerity of Hong Kong & Hong Kong \\
\hline Lixin Cai & $\begin{array}{l}\text { Pediatric Epilepsy Center, Peking University First } \\
\text { Hospital }\end{array}$ & Beijing China \\
\hline Jianxiang Liao & Shenzhen Children's Hospital & Shenzhen, China \\
\hline Yi Wang & Children's Hospital of Fudan University & Shanghai, China \\
\hline Hsin-Hung Chen & Taipei Veteran's General Hospital & Taipei, Taiwan \\
\hline Kensuke Kawai & Jichi Medical University & Japan \\
\hline Chun Kee Chung R & Seoul National University & Seoul, Korea \\
\hline Benedict M Selladurai & Hospital Universiti Kebangsaan Malaysia & $\begin{array}{l}\text { Kuala Lumpur, } \\
\text { Malaysia }\end{array}$ \\
\hline Piradee Suwanpakdee & Phramongkutklao hospital & $\begin{array}{l}\text { Bangkok, } \\
\text { Thailand }\end{array}$ \\
\hline
\end{tabular}

Table III. Levels of Care

Level 1.

$\underline{\text { Complexities }}$

Age:

Children aged 9 years and older 


\section{Etiology:}

Tumors

Focal cortical dysplasia (discrete)

Cavernoma

Hippocampal sclerosis (isolated in medial TLE)

Cysticercosis

Lesion characteristics: well demarcated

Procedures:

Lesionectomy

Temporal lobectomy

Amygdala-Hippocampectomy

Convexity away from eloquent cortex

VNS

Competencies

Personnel:

Child neurologist

Pediatric epileptologist

Pediatric neurosurgeon

Pediatric neuroradiologist

Anesthesiologist skilled with children

Social worker

Equipment:

Routine EEG

Prolonged video EEG

CT

MRI 1.5T 


\section{Facilities:}

Designated Pediatric Beds (may be within an adult hospital),

Pediatric ICU

Experience:

Evaluate minimum of 100 epilepsy patients/year

Minimum 15 resections/year

\section{Level 2 (includes all Level 1)}

\section{$\underline{\text { Complexities }}$}

Age:

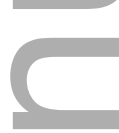

Children aged 8 years and younger

\section{Etiology/Lesion characteristics:}

Hippocampal sclerosis associated with dual pathology

AVM

Encephalomalacia (which may reflect prior ischemic or other injury)

Post inflammatory (including post infectious)

Rasmussen's encephalitis

Hemispheric malformation of cortical development

Tuberous sclerosis complex

Sturge Weber

Hypothalamic hamartoma

Poorly-demarcated lesions (unclear margins/borders)

MRI negative

Location/procedures:

Extra-temporal lobar 
Multi lobar

Hemispheric

Multifocal

Interhemispheric

Subcortical

Insula

Basal brain regions

Involving eloquent cortex

Lesion (or non-lesional) resection

Lobectomy

Multi-lobar resection

Hemispherectomy

Multifocal resection(s)

Deep Brain Stimulation

Responsive Neuro-Stimulation

Clinical Characteristics of children undergoing epilepsy surgery:

Encephalopathy

Developmental regression/epileptic encephalopathy

Associated developmental or medical syndrome

Genetic abnormalities

Complicated medical problems/(including those medically ill)

Ongoing status epilepticus

Personnel:

Child neurologist,

Pediatric epileptologist (minimum 2)

Pediatric neurophysiologist

Pediatric (epilepsy) neurosurgeon (minimum 1) 
preferably trained in functional/stereotactic epilepsy neurosurgeon

Pediatric neuropsychologist

Child psychiatrist

Pediatric neuroradiologist

Pediatric anesthesiologist

Epilepsy neuropathologist

Social worker

Pediatric neurology nursing

Nutritionist/dietician

Coordinator

Technology:

Routine EEG

Long-term video-EEG

CT

MRI 3T

Functional MRI

White Matter Tractography

Angiography

PET and/or SPECT

Some form of source localization capability (not specified between 3D EEG, MEG, or fMRI/EEG)

Cortical stimulation mapping (intra or extra-operative)

Invasive recording capability (intraoperative ECoG, subdural EEG, stereo-EEG)

Neuro-navigation

Resources/ Facilities:

Certified EMU (pediatric) (NOT on adult floor/service)

Dedicated pediatric services

PICU (NOT general ICU)

Rehabilitation facilities 


\section{Experience:}

Evaluate minimum of 225 epilepsy patients/year

Minimum 20 resections/year

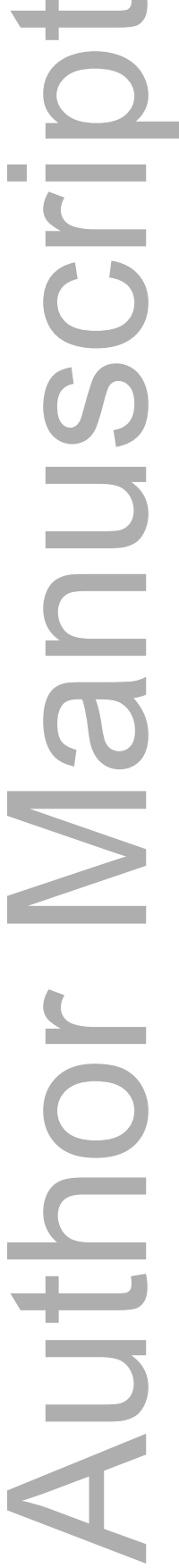

This article is protected by copyright. All rights reserved 


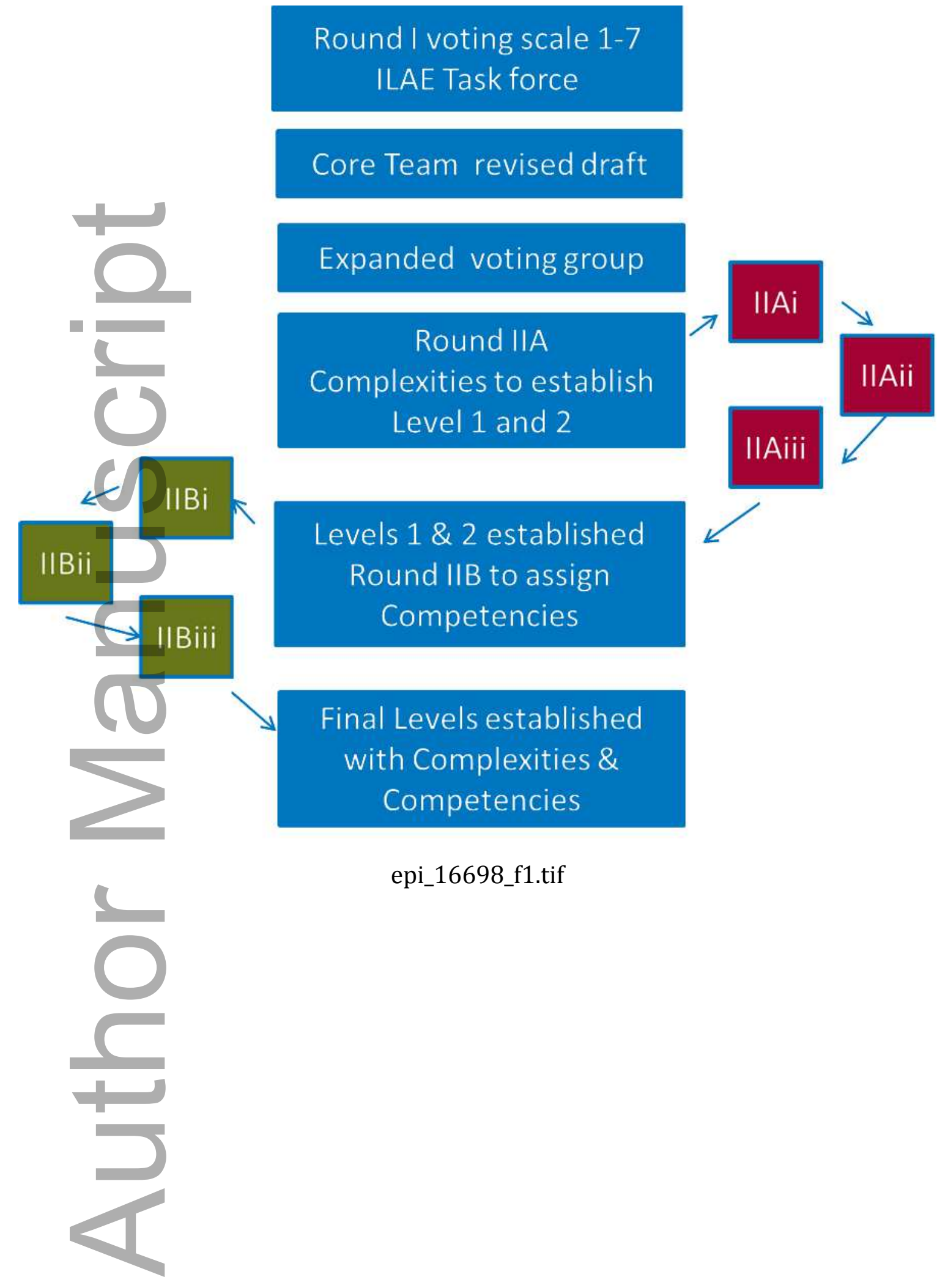




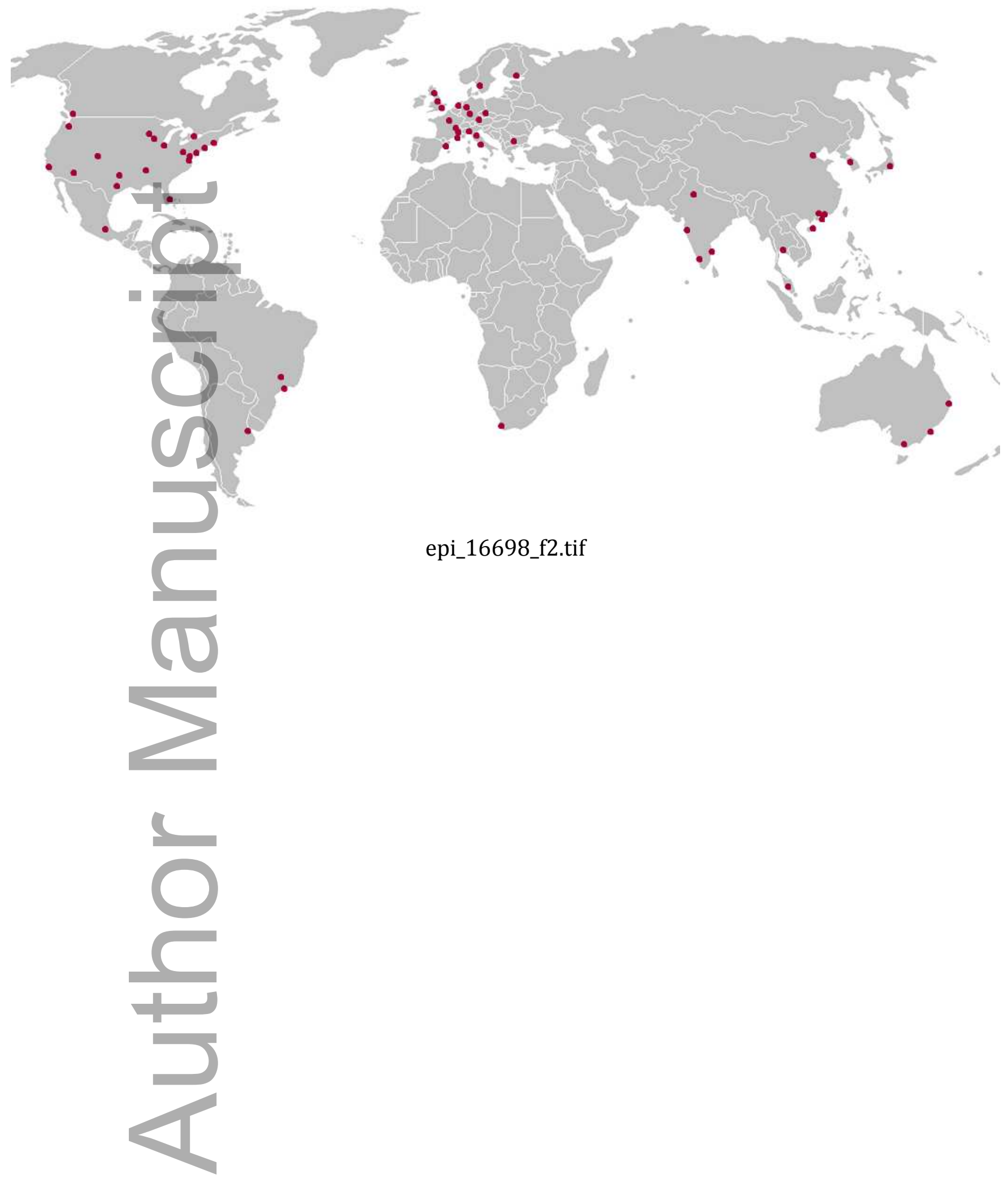

This article is protected by copyright. All rights reserved 


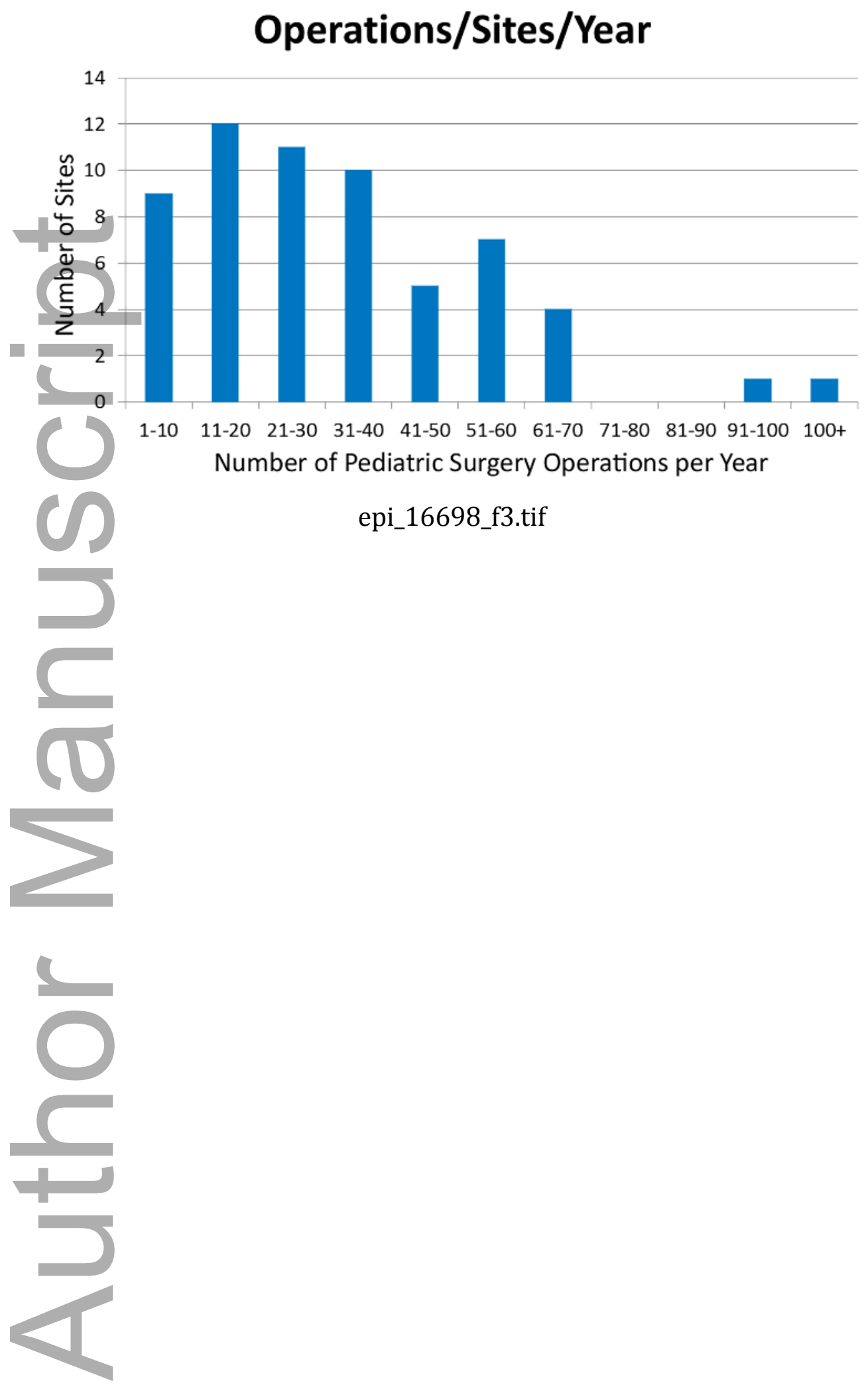

This article is protected by copyright. All rights reserved 


\section{University Library}

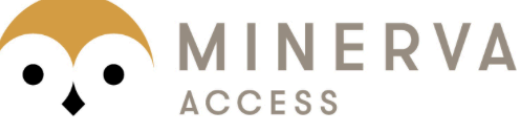

A gateway to Melbourne's research publications

Minerva Access is the Institutional Repository of The University of Melbourne

\section{Author/s:}

Gaillard, WD;Jette, N;Arnold, ST;Arzimanoglou, A;Braun, KPJ;Cukiert, A;Dick, A;Harvey, AS;Jacobs, J;Rydenhag, B;Udani, V;Wilmshurst, JM;Cross, JH;Jayakar, $\mathrm{P}$

Title:

Establishing criteria for pediatric epilepsy surgery center levels of care: Report from the ILAE Pediatric Epilepsy Surgery Task Force

Date:

2020-11-14

Citation:

Gaillard, W. D., Jette, N., Arnold, S. T., Arzimanoglou, A., Braun, K. P. J., Cukiert, A., Dick, A., Harvey, A. S., Jacobs, J., Rydenhag, B., Udani, V., Wilmshurst, J. M., Cross, J. H. \& Jayakar, P. (2020). Establishing criteria for pediatric epilepsy surgery center levels of care: Report from the ILAE Pediatric Epilepsy Surgery Task Force. EPILEPSIA, 61 (12), pp.2629-2642. https://doi.org/10.1111/epi.16698.

Persistent Link:

http://hdl.handle.net/11343/276613 